\title{
ARTS BASED INITIATIVES AS A HOLISTIC SOLUTION IN BUSINESS EDUCATION
}

\author{
Jel̦ena Maleško ${ }^{1}$, Olga Tjurdju ${ }^{2}$
}

\begin{abstract}
Global economic changes have caused employers to look for multidisciplinary and value-driven leaders who can provide a holistic development solution for business. Modern business institutions are challenged with a paradigm shift towards programs of integrity in applying student-centered holistic approaches in the acquisition and development of cross-disciplinary using reflective learning. This study explores the holistic effects and arts-based value of practices, integrated into business education for personal and professional students' development. Methods include a long-term research (3-years) involving focus groups, interviews, questionnaires, and observations that coincided with a theoretical analysis of conventional methods applicable to business education. Results show that arts based initiatives (ABIs) foster integrated development of skills that generate a strong holistic effect of multi- and inter-disciplinary. These are combined with powerful personal development, as ascertained in 360-degree reviews. It is concluded that an individual's transformation, achieved through ABIs, can impact on team dynamics as well as the organizational strategy and performance, and generates a 'spill-over effect' between individual, team, organization, and community, thus ascertaining the value of holistic approach in business education.
\end{abstract}

UDC Classification: 3.378, DOI: http://dx.doi.org/10.12955/cbup.v4.779

Keywords: holism, ABIs, inter-disciplinary, business education.

\section{Introduction}

In today's rapidly changing economies, organizations are searching for new, innovative strategies and managerial approaches to compete and create value. Many researchers state that the successful 21st century organizations will be those developing highly integrated creative competencies, able to generate and apply new entrepreneurial ideas, and manage and drive their energy and emotional state towards value creation dynamics of an enterprising culture (Boyatzis, Stubbs, \& Taylor, 2002; Bruch \& Ghoshal, 2003; Cross, Baker, \& Parker, 2003; Gratton, 2011; Steers, Mowday, \& Shapiro, 2004). An enterprising culture is now considered one of the 'success pillars' giving rise to new forms of 'sapient' leadership (Shaughnessy, 2011; Kirby, 2004). In their research, Timmons (1989), Halfhill and Nielsen (2007), and Kachra and Schnietz (2008) agreed there was a need for integrated, holistic managers who see opportunity, take risk, take charge, create, build, initiate, and achieve. In addition, an enterprising culture is fostered by people who are not only comfortable with change, but are persistent, enthusiastic, and inspiring, as well as focused on the long-term, use power and influence, create learning culture, collaborate, sell ideas, enhance commitments, and use a participativecollaborative style (Adler, 2006). However, Adler (2006) added that enterprising culture should also integrate value dimensions, such as, passion, emotions, hope, morale, imagination, aspiration, and creativity as new strategic organizational value drivers. Melé and Sanchez-Runde (2011) stated that integrating business and human facets of management, i.e., personal development and soft skills, generates holistic management that promotes core values, such as, emotional awareness, shared perspectives, empathetic leadership, benevolence, centeredness, and fulfilment, as well as tolerance, flexibility, creativity, authenticity, and integrity. Shefy and Sadler-Smith (2006) concluded that personal change in managers and leaders towards higher integrity of 'soft' and 'hard' skills in their core values may create enterprising culture. This would facilitate a desired change, as well as contributing to an organization's competitive advantage (Michalisin, Karau, \& Tangpong, 2004).

\section{Literature Review}

Holism, a philosophical concept derived from the Greek root 'holos', means: a whole with a value greater than the sum of its parts (Patterson, 1998). Patterson (1998) identified holism as the ability to "self-organize, self-renewal and self-transcendence, ability to assertively integrate with the whole". A holistic approach implies a system where a whole determines how its parts behave in encompassing

\footnotetext{
${ }^{1}$ Jel̦ena Maleško, RISEBA, 3 Meža Str., Riga, Latvia, lenam54@inbox.lv

${ }^{2}$ Olga Tjurdju, RISEBA, 3 Meža Str., Riga, Latvia
} 
and integrating multiple layers of meaning and experience. Holistic education engages students in the teaching and learning process, encourages personal and collective responsibility in developing the whole person, his or her physical, emotional, mental and spiritual levels, i.e., using their 'multiple intelligence', insight, rationality, logic, emotion, intuition, creativity, a sense of harmony, communication, and information from all their senses (Sambamurthy, Bharadwaj, \& Grover, 2003). While discussing the importance of a holistic approach in business education, Kirby (2004) described it as a key tool in creating an enterprising educational environment aimed at integrating the development of a student's 'multiple intelligence', inter-disciplinary competencies and 'soft' skills, multiple perspectives with vision, and other leadership skills. This seems to meet the definition of holistic leaders by Melé and Sanchez-Runde (2011) as those who integrate their inner resources, e.g., intellect, insight, intuition, imagination, and outer resources in their natural, social, and political environment. Rae (2000) suggested that numerous entrepreneurial and leadership traits can be learnt by students engaged in a holistic, enterprising learning environment that provides opportunities to examine ethics and values. This in turn ensures a holistic understanding of the business environment (Gupta \& Bharadwaj, 2013). A holistic approach to business education creates synergies produced through interaction and integration of individuals, and engages the resources and environmental factors as part of the whole system.

Harvey and Knight (1996) stated that the fundamental challenge of holistic education is to evoke a paradigm shift towards a student-centered integrated approach, by 'enhancing participants', 'adding to their capability value', 'empowering', supporting, and challenging thinking in new, creative enterprising ventures that ensures higher self-actualization, transformation, and other holistic perspectives. Boden and Marton (1998) and Dart and Boulton-Lewis (1998) suggested that the value of learning is realized through discovering students' ways of seeing and treating a phenomenon. Another value is students' recognition of their own knowledge development that builds capabilities for them to engage in effective actions in all domains of knowledge. The core values to develop in applying a holistic model are commitment, collaboration, and transformation. The factors essential to holistic education and their implications are 1) students learn about themselves through reflection, it is transformative learning; 2) they learn about relationships using social and emotional 'literacy'; it implies the idea of connections and interdependencies developing interdisciplinary approach to education; 3) students learn to overcome difficulties when facing challenges on the way to achieving professional and personal growth; and 4) they learn about community as an integral aspect in holistic education (e.g., classroom, school, and city) as well as esthetics that encourages them to appreciate and enjoy the beauty of the world around them (Weber \& Englehart, 2011).

The purpose of this research is to explore and identify the holistic effects of arts based initiatives (ABIs) as an effective integrating and holistic educational tool contributing to synergies of an enterprising, innovative, and creative organizational culture; and how the development of these effects benefit students engaged in ABIs during their undergraduate studies.

According to Harvard Business Professor, Rob Austin, "The economy of the future will be about creating value and appropriate forms, and no one knows more about the processes for doing that than artists" (Austin, 2005, as cited in Adler, 2006). Ottensmeyer (2005) viewed the role of arts in an organization as a lever to support and drive organizational changes; increase competencies and potential and latent energy; and support development and transformation of tangible and intangible infrastructure towards value creation. These dynamics have a tangible effect through personal development, and knowledge-based assets, while intangible assets are culture, values, identity, brand recognition, morale, and motivation (Nissley, 2010).

While there is comprehensive research in the holistic effectiveness of ABIs in contributing to the corporate world (Darso, 2004), their integration in business education is limited, but no less essential. The integration of ABIs in business academic curriculum is seen as a highly effective experiential holistic educational tool for developing students' competencies, skills, and personal characteristics and contributing to the institutional enterprising culture in the long-term. Arts based initiatives represent a holistic approach to learning since they provide the capacity to combine these major schooling functions: 1) transmission of facts, skills, and values; 2) transaction or dialogue between student and subject matter, resulting in reconstruction of knowledge; and 3) personal and social transformation (Bodwen \& Marton, 1998; Dart \& Boulton-Lewis, 1998). The Chinese proverb demonstrates the 
learning process: 'Tell me and I will forget. Show me and I may remember. But involve me and I will understand'.

The theory of Schiuma (2011) defines ABI as an organizational intervention using some art forms that engage people in an art experience within an organizational context. Researchers, Biehl-Missal and Berthoin (2011) assumed that ABIs, applied in business educational institutions, contributed a substantial holistic educational effect. This is primarily a powerful team-based learning experience that engages students both rationally and emotionally through either active or passive participation. It addresses issues of business education, which require intuitive thinking, emotional arousal, aesthetic understanding, social intelligence, creative capabilities, empathy, and flexibility among other skills and abilities. Positioning people in a different context, outside their comfort zone, encourages them to explore new ways and opportunities, and provokes thought, reflection, self-assessment, and new and different knowledge development (Schiuma, 2011). This leads to new insights, experiences, and skills, as well as shifts in applications, thus generating a strong holistic effect of multi- and inter-disciplines integrated with powerful personal development.

Sharma (1999) added that ABIs drive students' passion for novel ideas, their careful consideration of resources, and develops their open-mindedness, original thinking, critique, and reflection. Kanter (2004) wrote that ABI participants viewed it as a challenge towards innovation, making them stress resilient, enterprising, goal oriented, and seeking cost-efficient solutions. Arts based initiatives are reported as unlocking students' potential and leading to their integral growth, while enhancing their understanding of the school and broadening their personal experiences. Kanter (2004)

As a student-centered holistic mechanism, ABIs represent comprehensive projects that provide 'synthesis or aggregation' of information (Sanyal, 2001); students explore and connect the concepts and experiences obtained in the courses, and integrate these into real-life deliverables of practical use. Arts based initiatives provoke students' inner thinking and attitudes in the learning environment, allowing students to explore various perspectives simultaneously, reflecting upon and recognizing their strengths and weaknesses, exercising a range of abilities, yielding the most empowering, introspective, reflective, and intellectually multi-skilled experiences in integrity.

Creative in their nature, ABIs stimulate and integrate students intellectually and emotionally to develop 'big picture viewing', insight, and awareness, and foster the necessity and adoption of behavioral changes, generating 'creative intelligence' and emotional and practical values (Daum, 2005). As team based activities, ABIs engage a participant's head and heart in building team cohesion through various communications, confidence, and trust (Wali, Severson, \& Longoni, 2002). Thus, learning becomes much more integrated, as well as meaningful and memorable. South (2009) and Nissley (2010) wrote of the ABIs' holistic value in assisting collective problem-solving under pressure. Furthermore, entrepreneurial and leadership competencies, integrated and developed through ABIs, are based, not on intellectual or technical abilities, but on managing one's self, and forming relationships with others, i.e., emotional intelligence, such as, self-awareness, self-management, improvisation, empathy, and social skills providing the 'and or also' solutions for dealing with conflict. Arts based initiatives integrate rational-analytical skills with creative flare, resulting in a participant expressing new behaviors and this in turn improves relationships as well as the behaviors of others and organizations as a whole. Marton (2000) and Buswick (2005) stated that, while driving people out of their 'comfort zone', ABIs help develop people's ability to connect with their audience; develop empathy, confidence, maturity, and other advanced behaviors for managing the message, and discussing, convincing, and creating effective communication, leading to increased commitment. From a social point of view, ABIs' holistic effect is displayed in how students connect with a community mind-set and reflect on how their engagement in ABIs also benefits the institution and community at large (Steiner \& Watson, 2006). This strengthens their social responsibility, ethics, and character (Godfrey, Merrill, \& Hansen, 2009). Developing identity and understanding of an organization, team, and individual business landscapes are other valuable contributions of ABIs to students' professional, personal and emotional integrity (Govekar \& Rishi, 2007).

In summary, Nissley (2010) stated that ABIs provide a unique, but holistic development solution and synergy of business skills, integrated with mental and emotional dynamics. Artistic projects foster a wide scope of integrated skill development for discovering fresh opportunities to create new 
knowledge and experiences, and internationalizing them through artistic endeavors that create added value for students, institutions, and society from both short- and long-term perspectives. German artist and art theorist, Beuys (1975), added that artistic processes and 'creative' role models become a necessary precondition for personal development, with holistic thinking and employment skills provide the integration that other types of intervention lack.

\section{Arts Based Initiatives (ABIs) Concept in Practice}

According to Professor Schiuma's theory (Schiuma, 2011), ABI is considered a certain artistic initiative, applied and delivered in an academic context of varying scope and tempo. Coupled with Schiuma's three forms of ABIs (intervention, project, and set of projects), this paper's authors identified, for a business educational institution, these following forms of ABIs:

1. Regularly integrated arts based projects devoted to certain events, performed by students as a sustained tradition; and

2. Arts based activities integrated into the study process.

As a team-based learning process, engaging people rationally and emotionally, ABIs are viewed as a highly integrating and holistic educational tool in developing 'a new personality' (Schiuma, 2011). Arts based initiatives also lead to new organizational insights and experiences, contributing to the synergies of an institution's culture, due to their 'spill-over' effect.

The authors of this paper assumed that in business educational institutions the 'spill-over' effect is highly essential because today's youth are more responsive and enthusiastic towards challenges of teamwork, innovation, creativity, self-realization, and emotional engagement. Socially oriented and encouraged by the environment (school and community) today's youth are ready to apply their competencies in a different dimension of activities, motivated not only by ABIs, but also by tangible results in their professional and personal development. Based on a number of surveys, South (2009) described 'Generation Y' (today's students) as tending to blend their studies, work, and personal lives, and as fairly impatient, i.e., constantly wanting to develop and be challenged, and prepared for change that offers them meaning.

Figure 1: Arts based initiatives influences on today's youth

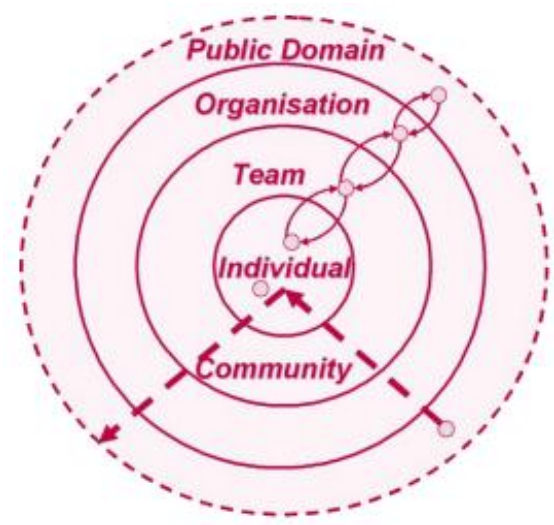

Source: South (2003)

Researchers, Biehl-Missal and Berthoin (2011) claimed that ABIs may serve, not only as a holistic educational tool in business education, but as a 'spill-over' effect (as described by Schiuma, 2011) that provided an overall holistic effect on the institutional level. This benefit permeated through integrating experiential and holistic learning at an individual level and contributing experiential learning at a group level, as well as from the increased experience and reach of a higher-level learning environment. When combined with reach at an organizational level, the holistic learning effect of ABIs involves a free flow of competencies from students with diverse business concepts and experience, providing the experience of creative, intuitive, and lateral thinking, and 'right-brain' skill development (Bragg, 2005). According to Kolb (1984), experiential learning theory (ELT), such as a holistic framework, assists students to build upon their individual characteristics, through offerings of the various 
components of the model that amalgamates the benefits of all to yield a new pedagogical model. Schiuma, (2009) and Biehl-Missal and Berthoin (2011) added that ABIs can also induce 'aesthetic' competence in the wider society in which the organization is embedded.

It is assumed that the most powerful effects are at the individual level, i.e., student ABI participants; with their experiences impacting teams (group level), organizational assets and resources, and further impacting the wider society (Schiuma, 2011).

According to Arts and Business (2004) there are two modes of ABI impacts: technical mode, namely, transfer of skills and knowledge, and an inspirational mode, as suggested by Schiuma (2009) of a new role model and novel ways of thinking that appear to integrate on both personal and organizational levels. A variety of ABI effects on an individual were observed by ABI participants, tutors, and faculty personnel. These mainly included training and personal development that generated personal growth through knowledge and skills application and development, and included discovering and implementing hidden skills, as well as strong emotional transformations. Arts based initiatives, in a highly challenging, motivating and holistic learning environment, evoke students to create and explore, and generate a significant multi- and interdisciplinary effect of integrating and developing professional competencies, personal growth, discovering and implementing hidden skills, gaining aesthetic competence, and engaging strong emotional transformations. The initiatives involve searching for alternative, better, and unconventional approaches; reflecting on attempts to view an issue from a different, broader perspective; learning from mistakes and failures; realizing routes to success; relating seemingly unrelated ideas to a problem for generating a solution; and thus, gaining the ability to focus on areas in need of change. From an emotional view, while performing in teams in new ways, the ABIs include sharing and influencing each other by galvanizing or inspiring, evolving new emotions, changing perspectives, causing reflection, critical thinking, and generating passion, intensity, and concentration. Such processes lead to better understanding of one-self and colleagues, self-discipline, sense of responsibility, self-recognition, and self-esteem. New communication and interaction patterns improve communication, team participation, intrinsic motivation, and commitment. This in turn affects students' attitudes towards studies, school, and community, leading to further skills and personal development, and creating a 'spirit of innovation', creativity, and enterprise, i.e., more significant, medium-level, people who initiate effect. Arts based initiatives are entertaining, but learning can occur because of ABIs' holistic effect on students and school (in terms of business skills as well as the mental and emotional dynamics), causing individual and group transformation, although this effect is limited.

Arts based initiatives contribute to a continuous learning culture, where students discover new ways of experiencing their studies by transferring a wide scope of knowledge, insights, and experiences, to develop in a holistic way.

At the group level, the impacts observed are improved communication, team building and bonding, and improved group identity. For example, mutual understanding and shared values can be developed by communicating about the artistic experience, work related issues, existing conflicts, and improved understanding of the connection between different programs and departments (Biehl-Missal \& Berthoin, 2011; Styhre \& Eriksson, 2008). As highly interactive team based activities, ABIs create trust and bonding, prompting people to leave their comfort zones and collaborate in different ways, creating group identity, addressing and solving conflicts, and thus improving communication and overall relationships between students and individuals of faculties and community, to create shared space and values. Arts based initiatives promote cultural values, respect for diversity, trust between people, and build cohesion and an ethic of solidarity (Wali, Severson, \& Longoni, 2002). Thus, they can contribute to a person's sense of connectedness and generate community organization with prestige and absorption of new values and culture.

At the organizational level, ABIs are expected to develop organizational assets and operational and dynamic capabilities (Schiuma, 2011). Tangible assets may be enhanced, e.g., information and technology (IT) and communication infrastructure, as well as intangible assets of organizational culture, reputation, and morale. This study's authors believe that continuous integration of ABIs into business education affects all dimensions, accelerating creativity, creating capacity for innovation, and supporting a holistic approach to learning that leads to creating values, enhanced organizational 
performance, and an institution's infrastructural transformation. Uniting people towards the same direction creates a long-lasting effect (Schiuma, 2011) that accelerates creativity, innovation, and change throughout the organization (Jensen, 2015). According to Arts and Business (2004), the two modes, technical and inspirational, integrate all organizational levels. Schiuma (2011) stated that, by influencing organizational performance, ABIs can affect the public domain, fostering the growth of community spirt and strengthening stakeholder relationships.

\section{Literature Review: Section Conclusions}

The above review reveals arts-based learning has recently gained recognition as a holistic tool and value for students' professional inter- and multi-disciplinarity, as well as for personal development. In existence since the 1950s, ABIs are, only now, gradually being adopted by educational institutions as part of curriculum. Nonetheless, little research data is available on the mid- and long-term holistic impacts of ABIs, especially for educational institutions. While this indicates a gap in knowledge, it also suggests an opportunity for research to explore the notion of ABIs as an educational tool in institutions and promote interest in arts-based initiatives in business education.

\section{Research Process, Methodology, and Design}

This research, exploratory by nature, was conducted over a 3-year period, involving Bachelor level students from three different programs, as well as faculty representatives, and members of staff, partners, and the public. The primary focus of our data collection and analysis was on both long-term (3 years) and short-term (one specific project) artistic activities. Short-term activities were more common, and allowed sustained effort and focus of the research topic. The data were collected via observations and reflection, questionnaires, focus group discussions, and interviews with all research participants and staff. Qualitative data analysis was performed in a deductive manner, i.e., by grouping the data to find similarities and differences of opinion and using content and narrative, and grounded theory analyses.

\section{Practical Implications: RISEBA Philosophy}

Established in 1992, in Latvia, the Riga International School of Economics and Business Administration (RISEBA) operated as a traditional business school for 15 years, with a strategic aim of preparing students for international management careers in Europe. However, the overall economic situation and growth in creative sectors required cardinal change to RISEBA's business model and changes to its concept and focus. The RISEBA's program portfolio shifted from its traditional business focus towards communications, media, and architectural studies, with a major block of the programs remaining business-oriented. This shift was a pioneering transformation from a small business school into a university "where business meets arts". Aiming to prepare competent and core value driven professionals, RISEBA has strived to ensure integrity of study programs that achieve a high level of synergy between business and arts. Integrative in its nature, their educational model ensures multi- and inter-disciplinarity, enhances student-centered holistic approach to education, and encourages an enterprising culture of creativity and innovation, and social cohesion in a multicultural environment based on trust, respect, and responsiveness. Such an integrating model provides potential opportunities for students and faculty members by continuous exposure and engagement of both, dimensions in the integrated arts-based activities and projects of different scales, internal and external, and thus fostering innovative, holistic approaches, and the ability to drive and manage novelty and change, risk, and diversity.

\section{Arts-Based Activities and Projects in RISEBA}

In compliance with RISEBA's innovative concept, in 2013, authors of this paper (also group tutors) undertook the initiative of engaging students in different arts-based projects (Table 1) on a regular basis with the aim to promote a more creative and innovative learning environment that would contribute and benefit a student's holistic development by integrating their core competencies of 'people' skills and personal, intellectual, and emotional growth, as well as contributing to RISEBA's enterprising culture and arrangement of holistic transformations.

Throughout all four projects (Table 1, see Appendix) the authors of this paper witnessed a growing galvanizing, learning, and emotional effects, generating integration, personal, and group transformations in professional and personal dimensions, since students were empowered to create and 
explore new ways of performing in teams, interacting, sharing, and affecting each other, united by the goal of this artistic experience. Tables 2 to 4 summarize the traits and skills, and the cross-dimensional and emotional experiences demonstrated in the projects described in Table 1.

Table 2: Projects affecting students' personal and professional development

\begin{tabular}{|c|l|}
\hline $\begin{array}{c}\text { Areas trained in } \\
\text { a holistic way }\end{array}$ & $\begin{array}{l}\text { Reflection, critical thinking, imagination, creativity, enterprise, and new perspectives } \\
\text { engaging all senses generated passion, determination, and group cohesion; developed self- } \\
\text { discipline, sense of responsibility, commitment, self-confidence and self-esteem. Proved a } \\
\text { rather long lasting holistic learning effect judging the students' transformation both at the } \\
\text { individual and group level. }\end{array}$ \\
\hline $\begin{array}{c}\text { Competencies } \\
\text { and personal } \\
\text { traits acquired } \\
\text { in a holistic way }\end{array}$ & $\begin{array}{l}\text { Development of new knowledge, skills, and personal traits in their integrity and } \\
\text { transferability; students practically faced the necessity to engage all senses } \\
\text { to transfer a wide scope of competencies, insights, and experiences from their } \\
\text { respective fields of studies to seemingly unrelated ones (business to arts and vice versa), } \\
\text { thus expanding and integrating not only their core competences and interdisciplinary } \\
\text { ones, but discovering and implementing new ones, gaining aesthetic competence, new } \\
\text { values, and awareness of abilities and new possibilities, and engaging strong emotional } \\
\text { transformations. Higher motivation to create and explore in an innovative and sharing } \\
\text { way. }\end{array}$ \\
\hline Enhanced areas & $\begin{array}{l}\text { Created trust, bonding, collaboration, shared vision and values, improved understanding, } \\
\text { relationships between students, and faculty and community individuals; individual and } \\
\text { group transformations created by interpersonal and intercultural bonds, networking, and } \\
\text { lasting inter-institutional bonds. }\end{array}$ \\
\hline General effects & Capacity built for new values, innovation, and drive on all levels \\
\hline Source: Author & \multicolumn{2}{l}{} \\
\hline
\end{tabular}

Table 3: 360-degree project assessment for Project 1

\begin{tabular}{|c|c|}
\hline & $\begin{array}{l}\text { From tutors' point of view, the main value of the project was the participants' self-recognition, self- } \\
\text { motivation, and sense of achievement. It created a 'can-do' attitude and appreciation of a creative, } \\
\text { motivational, and thought provoking power of the arts, which definitely contributed, to the group } \\
\text { enterprising and inspirational dynamics. The project ignited interest for further artistic endeavors } \\
\text { benefiting students' professional and personal development, and contributing to RISEBA's } \\
\text { interdisciplinary integrity, with enterprising and innovation driven spirit. }\end{array}$ \\
\hline & $\begin{array}{l}\text { Majority of the project's participants recognized its significant impacts and benefits: improvement of } \\
\text { core managerial/artistic competencies, ability to manage change and innovation, insights, and } \\
\text { approaches, general intelligence, self-organization, self-discipline, relationship and conflict } \\
\text { management, new approaches and perspectives, decision making, team building, cultural awareness, } \\
\text { ability to motivate and inspire, develop passion and commitment, self-awareness, confidence, all kinds } \\
\text { of communication, ability to interact and build rapport with the audience, linguistic competencies, and } \\
\text { technical and operational skills. }\end{array}$ \\
\hline & $\begin{array}{l}\text { Most participants' peers emphasized their improvement of managerial skills, communication, } \\
\text { leadership, and entrepreneurial competencies as well as initiative, creativity, and inspirational } \\
\text { characteristics, improved tolerance, conflict resolution, and general relations management skills. }\end{array}$ \\
\hline & $\begin{array}{l}\text { the group noticed the project participants' more active involvement in the study } \\
\text { proved understanding of core management and project competencies, communication } \\
\text { skills, creative, empathetic and critical attitudes affecting more engaged group } \\
\text { s became more demanding, critical, and aspiring for creative and innovative tasks, } \\
\text { themselves. Certain development of transferable skills was also noticed. However, } \\
\text { icipants (4) improved their academic grades. }\end{array}$ \\
\hline
\end{tabular}

Source: Author 
Table 4: 360-degree project assessment for Project 2

\begin{tabular}{|c|c|}
\hline & $\begin{array}{l}\text { From tutors' point of view, the main value of the project was the participants' recognition of their } \\
\text { potential, professional and personal development, personal and social values; recognition of failures } \\
\text { as opportunities and learning; drive for challenge, ability to realize the project under a very } \\
\text { restricted budget. Passion, remarkable emotional strain and engagement of all senses, hard work, } \\
\text { strive for success, overcoming resistance, bonding, enterprising and inspirational dynamics, open- } \\
\text { mindedness, trust and common sense ensured the project's success. The project evolved further } \\
\text { learning, creativity and desire for new artistic endeavors for core participants, other university students } \\
\text { and faculty. }\end{array}$ \\
\hline$\frac{\sqrt{H}}{\frac{1}{\sigma}}$ & $\begin{array}{l}\text { Improvement of core managerial and entrepreneurial skills, e.g., leadership, planning, organizing, } \\
\text { delegating, project management, logistics, time management, self-organization, working under pressure, } \\
\text { multitasking, marketing, advertising, decision-making, conflict-resolution, change management, } \\
\text { operations management, budgeting, research, team building, idea generation, flexibility, stress } \\
\text { management, risk management, cultural awareness, communication, interviewing, business ethics, } \\
\text { linguistic competencies, script writing, directing, acting, editing, shooting, and many other arts related } \\
\text { skills. They admitted a considerable improvement of self-awareness, confidence, critical thinking, } \\
\text { creativity and unorthodox approaches, loyalty, tolerance, perseverance, and striving for success. } \\
\text { Performing outside their comfort zone made them highly emotionally involved and personal } \\
\text { transformations were reported. }\end{array}$ \\
\hline$\frac{\frac{r}{T}}{\frac{1}{\Delta}}$ & $\begin{array}{l}\text { All participants' peers were impressed by the project's successful outcome and emphasized their peers } \\
\text { had improved professional skills, team-playing, multitasking, initiative, creativity and inspirational } \\
\text { characteristics, as well as improved communication, tolerance, conflict resolution, and relations } \\
\text { management skills. Sharing, cooperation, and empathy were also identified as improved. }\end{array}$ \\
\hline 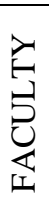 & $\begin{array}{l}\text { Most teachers appreciated the project participar } \\
\text { building, communication and organizational } \mathrm{s} \\
\text { Still, personal development appeared to be } \mathrm{m} \\
\text { intuition, broadened perspectives, unconventior }\end{array}$ \\
\hline
\end{tabular}

Source: Author

Table 5: 360-degree project assessment for Project 3

\begin{tabular}{|c|c|}
\hline 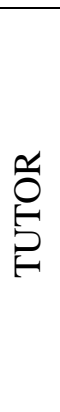 & $\begin{array}{l}\text { From tutors' point of view, the project contributed immensely to participants' } \\
\text { professional competencies - improved, acquired, and implemented many new skills, } \\
\text { especially in marketing and promotion, applying those in variety of functions, which } \\
\text { was evident of multitasking, transferability, and inter-disciplinarity. Personal } \\
\text { development was the most rewarding aspect: strive for novelty and challenge, } \\
\text { autonomy in decision-making and unconventional approaches, self-motivation, strive } \\
\text { for autonomy, perfection and success, teamwork, trust, effective communication, and } \\
\text { definitely insightful and inspiring artistic nature, with significant growth of social and } \\
\text { personal intelligence and integrity. }\end{array}$ \\
\hline$\underset{⿱ 山}{\sqrt{5}}$ & $\begin{array}{l}\text { All project participants recognized and appreciated its extraordinary impacts: } \\
\text { improvement of their professional competencies in management, marketing, } \\
\text { advertising, entrepreneurship, accounting, logistics, project management, liaison } \\
\text { management, change and innovation management, operations management, stress } \\
\text { management, human resource management, business administration, risk } \\
\text { management, time management, IT, negotiations, spoken and written communication, } \\
\text { and linguistic competencies. Participants strongly recognized the development of their } \\
\text { transferable and multitasking skills because of new ways of learning in a new } \\
\text { environment, and motivation to experiment. Students commented that the project } \\
\text { contributed significantly to their personal development: they improved self-awarenes, } \\
\text { realized their potential, became more challenging and innovative, ambitious, outgoing, } \\
\text { confident, flexible, sensitive to arts, insightful, and creative. }\end{array}$ \\
\hline
\end{tabular}




\begin{tabular}{|l|l|}
\hline & $\begin{array}{l}\text { All participants' peers were impressed by the project's extraordinary success and } \\
\text { expressed their gratitude for the event. Peers reinforced the participants' self- } \\
\text { evaluation of their professional and personal skills: improved entrepreneurial, } \\
\text { managerial, leadership, and artistic skills in their growing integrity and transferability. } \\
\text { Most peers stated that participants' behavior, attitudes, and emotional transformations } \\
\text { positively impacted, not only group morale, but also the overall school environment. }\end{array}$ \\
\hline Source: Author & $\begin{array}{l}\text { Faculty representatives recognized a considerable improvement of professional } \\
\text { competencies, especially in marketing, management, project management, and } \\
\text { communication. Personal development was emphasized, e.g., confidence, insightful } \\
\text { attitudes, ability to take charge, initiative, critical thinking, imagination, intuition, and } \\
\text { flexibility. Some faculty members expressed a desire to participate in future ABIs and } \\
\text { engage in the groups' academic activities. }\end{array}$ \\
\hline
\end{tabular}

\section{Results and Discussion: Individual Level}

The most powerful and evident impacts of the holistic value of ABIs for students were the observed interpersonal relationships. The students recognized the value of their personal changes and those of their peers. Arts based initiatives also generated value for group dynamics and the institution. Students also learnt a great deal about themselves and their colleagues and became more passionate about further professional and personal growth, as well as school development. Arts based initiatives stimulated the students to explore and experiment by engaging in rational and emotional dimensions. The initiative to organize ABIs shifted from faculty personnel to students. Arts based initiatives broadened the students' perspectives and ability to think in unconventional ways, discover fresh ways of learning in a new environment, and increase motivation, commitment and self-organization. Students developed recognition of their own centrality as individuals and members of society. They viewed themselves, and were perceived by others, as multifaceted individuals that enhanced their selfesteem, self-confidence through achievements, satisfaction, overcoming issues, interactions, and communications. They developed new kinds of competencies in new ways, thus generating multi- and cross-disciplinary effects, as well as abilities to discover and a desire to build on potential capabilities. Students also developed interest in cultural and social issues and engaged professional competencies and creative and reflective behaviors, resulting in significant skill transfer. Their creativity, imagination, emotional, and inspirational arousal enhanced, while emotional intelligence, empathy and tolerance also improved.

\section{Team Level}

The impacts and holistic value of ABIs for teams was somewhat remarkable due to improved communication, understanding, and relationship development and efficiencies. Intensive interaction, networking, and common vision, strengthened team cohesion and thus, benefited the learning culture. Broadened shared vision evolved unconventional approaches and innovations. Arts based initiatives facilitated team interaction and collaboration across functions and cultures, and unified diverse ideas and perspectives. The team also developed a socialization process from concept to execution, facilitating the synthesis of individual and group vision, identifying the interdependencies and connections, and resulting in a common vision. By being engaged in ABIs, the students shared and learnt new skills, which facilitated teamwork and collaboration, and developed a deeper personal presence and connection among team members, through involvement and commitment.

Students recognized their personal skills, abilities, and value as team members contributing to the team effect, and experienced a strong emotional and inspirational team impact. They also appreciated their role and responsibility in maintaining unity and cohesiveness, coordinating and integrating their actions very carefully, considering different perspectives, communicating different points of view, and examining and making sense of the whole process. Students discussed the process and skills learnt and applied. They experienced a complete project process by reflecting on and improving skills, and facilitating successful teamwork that accelerated trust and bonding. 
Table 6: 360-degree project assessment for Project 4

From tutors' point of view, the main value of the project was considerably improved professional and personal skills, especially planning, organizational and time management skills, coordination, delegation, and communication that especially benefited team playing. Enhanced leadership, entrepreneurial, and cross-cultural and integrating skills contributed to a very successful involvement of new team members, their inspiration, self-recognition, and the overall igniting and bonding effect. Prior experience resulted in higher autonomy, sense of

$\approx$ responsibility and diligence, shift of initiative, increase in creativity, research, artistic skills, and language competencies. The project was evident of considerably improved multitasking, transferability, and inter-disciplinarity, as well as extraordinary emotional involvement and flexibility students who performed and switched between a variety of functions. Integration of rational/insightful approaches with intuitive/emotional involvement proved highly effective in all aspects of the project. Personal and group development was the most rewarding aspect, increasing an individual's striving for novelty, challenge and success, autonomy, commitment, reveal of potential, learning and artistic experience, tolerance, trust, interdependence, communication, and self-esteem.

All project's participants recognized and appreciated its extraordinary impacts: improvement of their professional competencies in management, marketing, entrepreneurship, logistics, project management, liaison management, change and operations management, stress management, human resource management, time management, negotiation, communication, and linguistic and cross-cultural competencies. Participants recognized further development of their transferable and multitasking skills. They commented on their considerable personal development effect: self-awareness, self-esteem, recognition and realization of their potential, increased challenge and creativity, confidence, flexibility, improved relationship, empathy, and sensitivity to arts. Some participants stated they became involved in the entrepreneurial activities due to artistic projects.

All participants' peers were impressed by the project's extraordinary success and expressed their admiration; peers reinforced the participants' self-evaluation of their professional and personal growth in improved entrepreneurial, managerial, leadership and artistic skills in their growing integrity, and transferability. Most peers stated that participants positively impacted, not only group morale, but also the overall environment.

Faculty representatives recognized the participants' maturity, further professional and crossdimensional competencies, especially in project management, and communication. Personal development was emphasized, e.g., confidence, insightful attitudes, ability to take charge, initiative, critical thinking, 'big picture' viewing, flexibility, and teamwork. More faculty members recognized the ABIs' strong holistic value in business education; some staff started engaging ABIs in their groups' academic activities.

Source: Author

\section{Institution Level}

The ABIs' integrating effect was noticeable in the improved communication and collaboration between individuals at all institutional levels and functions. The ABIs helped to bridge cultural differences, facilitating rational thinking across cultures, and encouraged innovation and change. Arts based initiatives integrated and developed tangible and intangible assets, e.g., IT, communication, morale, and culture. They improved the learning climate, motivated more students to participate in the ABIs, motivated staff and faculty representatives to use the ABIs as a holistic tool, and unified diverse ways of thinking and creating new meaning. Arts based initiatives developed identity and recognition for the institution by enhancing competitiveness, helping adaptation to change, proactively shaping strategies, building trust, understanding, support, and connected teams, and improving commitment. They also contributed to shared vision and values of generating new ones, changing mind-sets, and attitudes driving innovation and change. Arts based initiatives strengthened commitment through 
recognition and inspiration by schools, and in team dynamics, increased innovative effectiveness and shared vision, which are closely related.

\section{Community Level}

Arts based initiatives' effect on community was also observed in the prolonged arousal of interest and inspiration, improved relationships among stakeholders, aesthetic awareness, overall community spirit, and motivation to apply ABIs in organizations and institutions.

\section{Holistic Value Created by Integrated Effects}

The research findings showed the holistic value of the integrated effects of ABIs, with students' displaying enhanced recognition of themselves as citizens, who were able to influence the institution and the socio-economic and natural environment they interacted with. In addition, the environment also affected these ABIs institutions' and students' values and perceptions of culture and behavior in a new way. Therefore, it may be concluded that ABIs affected the environment and caused, not only a 'spill-over effect' (as described by Schiuma, 2011) but generated a 'holistic value of a collective vision' (Taylor \& Ladkin, 2009). Furthermore, involvement in ABIs affected faculty members, to a great extent, expanding their boundaries, scope of competencies, discovering their potential, new opportunities, and values of teaching and learning methods, which also indicated ABIs' holistic value on faculty.

\section{Research Limitations}

Arts based initiatives, their promotion and encouragement of staff to implement such required efforts and commitment of university administration have associated costs. Arts based initiatives required a curriculum re-structure to allow for additional activities and this affected the cost of the specialized learning. The ABIs have more elaborate program requirements and thus, can be difficult to implement due to faculty resistance, with poorly executed projects likely to jeopardize the reputation of an institution. It was difficult to measure and evaluate ABIs' impact due to their complex nature, influence of other factors, and outcomes that usually have delayed effects. Artistic processes cannot be fully controlled and results may reflect confounding effects. Ideally, ABIs require the freedom, trust, as well as the specific knowledge, skills, and (mainly) personality type to manage them.

The discussion and results of this study, suggest a need for further co-operative study with independent researchers, committed to evaluate the effectiveness of artistic interventions, to gather and analyze data and identify potential barriers and difficulties in promoting ABIs. It is also necessary to seek further understanding of all stakeholders' values regarding ABIs and the preferred conditions for using ABIs, as well as the limitations and the appropriate forms of ABIs to generate these values and conditions. A more (self-) critical study that uses a participative research methodology and a mix of methods, such as action-evaluation research, case studies, and interviews (Antal, 2009), and other innovative arts-based methods is also proposed. Management needs to develop its capacity to create the environments in which students can engage with the arts. In concurrence with Senge (1994), the authors admit that students need personal mastery, i.e., empowerment to create and explore; mental models to challenge and find new ways of performing; team learning where most decisions are made by groups so they learn and explore together; shared vision; systems of thinking for understanding of how the actions from one team, program, study, or course would impact others. It is also important to develop and improve infrastructural mechanisms so that people have the resources, i.e., the ABIs, that they need to build new skills.

\section{Conclusion}

The holistic effects and value of ABIs in business education is notable as they provoke new thinking and reflection, emotional arousal, and transformation. Arts based initiatives generate transferability of knowledge and skills, create aesthetic and cultural awareness and values, foster students' and organizational resolve for innovation, creativity and lifelong learning. They also create challenges and seek changes to routines, overcome anxieties and resistance, and enhance aspirations for the future. Arts based initiatives build capacity for new values, innovation, and drive on all levels of networking to increase visibility and generate interest of potential students and partners. The significance of human values provided by and generated through ABIs reflects the holistic value they provide for interrelationships between individuals, groups and organizations, as well as their value for society. 


\section{References}

Adler, N. J. (2006). The Arts \& Leadership: Now that we can do anything, what will we do? Academy of Management Learning \& Education, 5(4), 486-499.

Antal, A. B. (2009). Research Framework for Evaluating the Effects of Artistic Interventions in Organizations. Tillt Europe Project.

Arts and Business. (2004). Whu business needs arts. London: Art works, Arts \& Business.

Beuys, J. (1975). Jeder mensch ein kunstler [Every human being is a kunstler].

Biehl-Missal, B., \& Berthoin, A. A. (2011). The impact of arts-based initiatives on people and organizations: research findings, challenges for evaluation and research, and caveats (Giełda Papierów Wartościowych Warsaw Stock Exchange uppl.). Warsaw, Poland: KEA - European Affairs, in Partnership with British Council.

Bodwen, J., \& Marton, F. (1998). The university of learning: Beyond quality and competence in higher educaton. London: Kogan Page.

Boyatzis, R. E., Stubbs, E. C., \& Taylor, S. N. (2002). Learning cognitive and emotional intelligence competencies through graduate management education. Academy of Management Journal on Learning and Education, 1(2), 150-162.

Bragg, M. (den 10-13 July 2005). Educating for, about, and through entrepreneurship: a case study for whole-brain curriculum development. paper presented at the Internationalizing Entrepreneurship Education and Trainining Conference (IntEnt2005). Guildford. Hämtat från www.intent-conference.com

Bruch, H., \& Ghoshal, S. (2003). Unleashing Organisational Energy. MIT Sloan Management Review.

Buswick, T. (2005). Seeing your audience through an actor's eyes: an interview with George Stalk. Journal of Business Strategy, 26(5), 22-28.

Cross, R., Baker, W., \& Parker, A. (2003). What creates energy in organisations? MIT Sloan Management Review, 51-56.

Darso, L. (2004). Artful creation: Learning tales of arts in business. Frediksberg, 13-22.

Dart, B., \& Boulton-Lewis, G. (1998). Teaching and Learning in Higher Education. Australian Council for Education Research, (ss. 103-123). Melbourne.

Daum, K. (2005). Entrepreneurs: the artists of the business world. Journal of Business Strategy, 26(5), 53-57.

Godfrey, P., Merrill, C., \& Hansen, J. (2009). The Relationship Between Corporate Social Responsibility and Shareholder Value: An Empirical Test of the Risk Management Hypothesis. Strategic Management Journal (30 (4)), 425-445.

Govekar, M. A., \& Rishi, M. (2007). Service learning: Bringing real-world education into the B-school classroom. Journal of Education for Business, 83 (1), 3-10.

Gratton, L. (2011). The Shift: The Future of Work Is Already Here. HarperCollins UK.

Gupta, N., \& Bharadwaj, S. S. (2013). Agility in business school education through richness and reach: a conceptual model. Education + Training, 55(4/5), $370-384$.

Halfhill, T. R., \& Nielsen, T. M. (2007). Quantifying the "softer side" of management education: An example using teamwork competencies. Journal of Management Education, 31, 64-80.

Harvey, L., \& Knight, P. T. (1996). Transforming higher education. Society for research into higher education and Open University Press.

Jensen, K. R. (2015). INSPIRING A COLLECTIVE VISION: THE MANAGER AS MURAL ARTIST.

Kachra, A., \& Schnietz, K. (2008). The capstone strategy course: what might real integration look like? Journal of Management Education, 32(4), 476-508.

Kanter, R. M. (2004). Middle Manager as Innovator. Harvard Business Review (July-August).

Kirby, D. A. (2004). Entrepreneurship Education: Can Business Schools Meet the Challenge? Education + Training, 46(8/9), 510-519.

Kolb, D. (1984). Experiential learning. Englewood Cliffs: NJ: Prentice Hall.

Marton, B. A. (2000). Releasing the artist within: developing creativity at work. Harvard business review (June-July).

Melé, D., \& Sanchez-Runde, C. J. (2011). Towards Holistic Understanding of Management. Journal of Management Development, 30(6), 544 - 547.

Michalisin, M. D., Karau, S. J., \& Tangpong, C. (2004). Top management team cohesion and superior industry returns. Group Org Manage, 29(1), 125-140.

Nissley, N. (2010). Arts-based learning at work: economic downturns, innovation upturns, and the eminent practicality of arts in business. Journal of Business Strategy, 31(4), 8-20.

Ottensmeyer, M. E. (2005). Solving business problems through the creative power of the arts: catalyzing change at Unilever. Journal of Business Strategy, 26(5), 14-21.

Patterson, E. F. (1998). The philosophy and physics of holistic health care. Spiritual healing as a workable interpretation. Journal of advanced nursing, 27(2), 287-293.

Rae, D. (2000). Understanding entrepreneurial learning: A question of how? International Journal of Entrepreneurial Behaviour and Research, 6(3), 145-149. 
Sambamurthy, V., Bharadwaj, A., \& Grover, V. (2003). Shaping Firm Agility through Digital Options: Reconceptualizing the Role of IT in Contemporary Firms. MIS Quarterly, 27(2), 237-263.

Sanyal, B. C. (2001). New functions of higher education and ICT to achieve education for all. Paris: International Institute for Educational Planning.

Schiuma, G. (2009). The Organisational Value of Arts. Arts \& Business.

Schiuma, G. (2011). The Value of Arts for Business. Cambridge: Cambridge University Press.

Senge, P. M. (1994). The Fifth Discipline Fieldbook: Strategies and Tools for Building a Learning Organization. Crown Business.

Sharma, A. (1999). Central dilemmas of managing innovation in large firms. Harvard Business Review.

Shaughnessy, H. (2011). The 5 pillars of the new enterprise operating system. Forbes Online Magazine Issue, 7. Hämtat från www.forbes.com

Shefy, E., \& Sadler-Smith, E. (2006). Applying holistic principles in management development. Journal of Management Development, 25(6), 368-385.

South, G. (2009). Mapping Arts-Based Initiatives: The value of arts based initiatives. London: Arts \& Business.

Steers, R. M., Mowday, R. T., \& Shapiro, D. L. (2004). Introduction to special topic forum: The future of work motivation theory. Academy of Management Review, 379-387.

Steiner, S. D., \& Watson, M. A. (2006). The service learning component in business education: The value linage void. Academy of Management Learning \& Education (5), 422-434.

Styhre, A., \& Eriksson, M. (2008). "Bring in the Arts and Get the Creativity for Free. A Study of the Artists in Residence Project. Creativity and Innovation Management, 17 (1), 47-57.

Taylor, S. S., \& Ladkin, D. (2009). Understanding arts-based methods in managerial development. Academy of Management Learning and Education, 8, 55-69.

Timmons, J. A. (1989). The Entrepreneurial Mind. Brick House Publishing.

Wali, A., Severson, R., \& Longoni, M. (2002). Informal arts: finding cohesion, capacity and other cultural benefits in unexpected places. Chicago, Illinois: Columbia College, Chicago Center for Arts Policy.

Weber, J. W., \& Englehart, S. W. (2011). Enhancing business education through integrated curriculum delivery. Journal of Management Development, 30(6), 558-568. 


\section{Appendix}

Table 1: Projects overview and scope

\begin{tabular}{|c|c|c|c|}
\hline Name & Description & Activities & Participants \\
\hline $\begin{array}{l}\text { 1.United } \\
\text { Colors of } \\
\text { Valentine } \\
\text { (Feb } \\
2014)\end{array}$ & $\begin{array}{l}\text { 40-minute performance staged on } \\
\text { RISEBA premises for fellow-students, } \\
\text { faculty and administration (audience } \\
100 \text { people). Plot based on most } \\
\text { famous, classical love stories of } \\
\text { different cultures, e.g., Romeo and } \\
\text { Juliet, Notre-Dame de Paris, The Gift } \\
\text { of the Magi, Tristan and Izolde, } \\
\text { Turaidas Roze also included scenes } \\
\text { from different cultures' traditions } \\
\text { related to romantic relationship in older } \\
\text { times and today }\end{array}$ & $\begin{array}{l}\text { The project involved a lot of arts- } \\
\text { based activities (script writing, } \\
\text { directing, performing, } \\
\text { scenography, video and music } \\
\text { design, premises decoration) and } \\
\text { business activities (planning, } \\
\text { organizing, budgeting, team } \\
\text { building, problem solving, } \\
\text { communication, promotion) }\end{array}$ & $\begin{array}{c}30 \text { students } \\
\text { (EBS and } \\
\text { AVM) } \\
2 \text { tutors }\end{array}$ \\
\hline $\begin{array}{l}\text { 2. Great } \\
\text { Brits in } \\
\text { Latvia in } \\
\text { the Past } \\
\text { and } \\
\text { Present } \\
\text { (Oct- Nov } \\
\text { 2014) }\end{array}$ & $\begin{array}{l}\text { In scope of a 7-day 'British Week' } \\
\text { project } 2 \text { films created: } \\
\text { Tribute to Sir George Armistead, } \\
\text { 4th Mayor of Riga (1901-1912)-a } \\
\text { 20-minute film based on historical } \\
\text { facts, documents, and evidences } \\
\text { Students' interviews of key } \\
\text { executives representing the British } \\
\text { companies in Latvia shot in their } \\
\text { respective premises }\end{array}$ & $\begin{array}{l}\text { Project design and management, } \\
\text { business plan, budgeting, } \\
\text { information research, analysis and } \\
\text { processing, script writing, } \\
\text { directing, performing, camera } \\
\text { work, shooting, editing, footage, } \\
\text { video and music design, technical } \\
\text { support, different kinds of liaison } \\
\text { and communication, promotional } \\
\text { activities, event management, } \\
\text { logistics. }\end{array}$ & $\begin{array}{c}35 \text { students } \\
\text { (EBS and } \\
\text { AVM) } \\
1 \text { tutor }\end{array}$ \\
\hline $\begin{array}{c}3 . \\
\text { 'Black' } \\
\text { Valentine } \\
\text { party } \\
\text { (Feb } \\
2015)\end{array}$ & $\begin{array}{l}\text { St Valentine's party - the event that } \\
\text { included a } 120 \text {-minute musical } \\
\text { performance followed by the students' } \\
\text { concert, games, competitions, lottery } \\
\text { and a disco - audience of about } 700 \\
\text { people }\end{array}$ & $\begin{array}{l}\text { Project design and management, } \\
\text { business plan, budgeting, } \\
\text { information research, script } \\
\text { writing, directing, performing, } \\
\text { Heavy and diverse promotion was } \\
\text { organized to attract students from } \\
\text { other universities, sponsors, } \\
\text { catering companies and charity - } \\
\text { RISEBA students had a full } \\
\text { autonomy working at the project } \\
\text { for } 3 \text { months, still coordinated and } \\
\text { assisted by the tutors and } \\
\text { administration. }\end{array}$ & $\begin{array}{l}50 \text { students } \\
\text { (EBS, } \\
\text { AVM, } \\
\text { Project } \\
\text { Mng) } \\
2 \text { tutors }\end{array}$ \\
\hline $\begin{array}{l}4 . \\
\text { Guy } \\
\text { Fawkes } \\
\text { Night } \\
\text { (Nov } \\
2015 \text { ) }\end{array}$ & $\begin{array}{l}\text { In scope of a 7-day 'British Week' } \\
\text { project a theatrical performance staged } \\
\text { on RISEBA premises for BritCham and } \\
\text { their members to celebrate one of the } \\
\text { major British traditions. First year } \\
\text { students' } 1^{\text {st }} \text { arts based project } \\
\text { involvement. }\end{array}$ & $\begin{array}{l}\text { The project involved a lot of arts- } \\
\text { based activities (script writing, } \\
\text { directing, performing, } \\
\text { scenography, video and music } \\
\text { design, premises decoration) and } \\
\text { business activities (project } \\
\text { management, logistics, planning, } \\
\text { organizing, budgeting, team } \\
\text { building, problem solving, } \\
\text { communication, conflict } \\
\text { resolution, promotion) }\end{array}$ & $\begin{array}{l}30 \text { students } \\
\text { (EBS, } \\
\text { AVM, } \\
\text { ERASMUS } \\
\text { stud.) } \\
1 \text { tutor }\end{array}$ \\
\hline
\end{tabular}

